\title{
OPTIMALISASI KINERJA MOTOR DIESEL DENGAN SISTEM PEMANASAN BAHAN BAKAR
}

\author{
Nana Supriyana \\ Program Studi Teknik Mesin \\ Sekolah Tinggi Teknik Wiworotomo Purwokerto \\ Email: Nana.sttw@gmail.com \\ Taufiq Hidayat \\ Fakultas Teknik, Program Studi Teknik Mesin \\ Universitas Muria Kudus \\ Email: ophiqhd@gmail.com
}

\begin{abstract}
ABSTRAK
Perkembangan dunia otomotif maka banyak pemikiran untuk memodifikasi supaya unjuk kerja motor lebih baik. Salah satunya dengan memanaskan bahan bakar yang dilakukan pada motor diesel, hal ini dilakukan untuk menurunkan viskositas bahan bakar supaya bahan bakar lebih cair dan bahan bakar mudah untuk di injeksikan serta lebih mudah bercampur dengan udara, sehingga daya yang dihasilkan lebih besar dan konsumsi bahan bakar akan lebih irit. Untuk menjawab hal tersebut maka dilakukan penelitian pemanasan terhadap bahan bakar sebelum pompa injeksi pada motor diesel satu silinder. Penelitian ini mendapatkan hasil bahwa daya meningkat sebesar $3,5 \%$ pada temperatur $55^{\circ} \mathrm{C}$ dan pada tempertur $65^{\circ}$ sebesar 3,8\% dari kondisi standart, serta torsi meningkat sebesar 3,5\% pada temperatur $55^{\circ} \mathrm{C}$ dan pada suhu $65^{\circ}$ torsi meningkat sebesar 3,84\% dari kondisi standart serta konsumsi bahan bakar menurun sebesar $3,5 \%$ pada temperatur $55^{\circ} \mathrm{C}$ dan pada temperatur $65^{\circ} \mathrm{C}$ menurun sebesar $29,4 \%$ dari kondisi standart.
\end{abstract}

Kata kunci: motor diesel, perubahan suhu, unjuk kerja.

\begin{abstract}
The development of the automotive world that a lot of thought to modify the engine better performance. One of these with heating fuel carried on diesel engine, this is done to reduce the viscosity of the fuel so that the fuel is more fluid and fuel easily injected as well as more easily mixes with air, so that the power generated is greater and fuel consumption will more economical. To answer that research is conducted before it the heating of the fuel injection pump in a diesel engine cylinder. This research get the result that power increased by 3.5\% at a temperature of $55^{\circ} \mathrm{C}$ and at $65^{\circ}$ temperture $3.8 \%$ of standard conditions, and torque increased by 3.5\% at a temperature of $55^{\circ} \mathrm{C}$ and $65{ }^{\circ}$ of torque increased by $3.84 \%$ from standard conditions and fuel consumption decreased by $3.5 \%$ at a temperature of $55^{\circ} \mathrm{C}$ and at a temperature of $65^{\circ} \mathrm{C}$ decreased by $29.4 \%$ from the standard conditions.
\end{abstract}

Keywords: diesel engine, temperature changes, performance.

\section{PENDAHULUAN}

Perkembangan dunia otomotif akhir-akhir ini sangat pesat. Perkembangan industri otomotif tersebut dapat kita lihat dari banyaknya produk-produk baru, baik mobil maupun sepeda motor yang ada dipasaran. Tentu saja dengan menghadirkan teknologi teknologi dan spesifikasinya. Dengan semakin meningkatnya perkembangan didunia otomotif maka jumlah kendaraan akan semakin meningkat sehingga berdampak pada lingkungan. Salah satu polutan dari proses pembakaran yang dapat menyebabkan polusi pada lingkungan adalah HC, CO dan Nox. Gas ini terbentuk oleh proses pembakaran yang tidak sempurna. Kandungan polutan gas buang dari kendaraan bermotor paling banyak di pengaruhi oleh ketidak sempurnanya proses pembakaran didalam silinder.

Tingginya konsumsi bahan bakar dan kadar polusi dari kendaraan bermotor pada dasarnya dapat dikendalikan dan dikurangi. Salah satu cara yang paling tepat adalah dengan cara memperbaiki proses pembakaran yang terjadi di dalam motor. Cara-cara yang dapat dilakukan antara lain dengan perbaikan mutu bahan bakar, homogenitas campuran bahan bakar dan mengatur saat pembakaraan yang tepat. 
Salah satu cara agar campuran bahan bakar dan udara lebih homogen yaitu dengan memanaskan bahan bakar, hal ini di maksudkan agar viskositas bahan bakar turun sehingga bahan bakar mudah di injeksikan kedalam ruang bakar dan membuat kerja dari poros engkol akan lebih ringan serta daya dari poros engkol dapat dimaksimalkan untuk menggerakan beban. Hal ini juga dimaksudkan agar bahan bakar akan lebih mudah bercampur dengan udara yang masuk ke dalam silinder sehingga homogenitas campuran bahan bakar dan udara akan lebih baik serta konsumsi bahan bakar akan lebih irit dan campuran bahan bakar akan lebih homogen.

Beberapa hasil penelitian terdahulu diantaranya dilakukan oleh Murni dari Universitas Diponegoro [1], telah melakukan penelitian di laboratorium Energi PSD Teknik Mesin Undip pada tahun 2010 dengan bahan bakar minyak sawit menyatakan bahwa, terdapat penurunan konsumsi bahan bakar dan pada terperatur yang lebih tinggi maka konsumsi bahan bakar menjadi lebih tinggi karena peningkatan temperatur sehingga bahan bakar menjadi lebih cepat terbakar.

Dalam penelitian Febrian Wiilyanto dari Universitas Kristen Petra Surabaya [2], telah melakukan penelitian dengan bahan bakar solar, menyatakan bahwa, dengan pemanasan bahan bakar membawa perubahan terhadap torsi, daya, konsumsi bahan bakar dan efisiensi thermis.

Peneliti Stefanus Okie Suharjo dari Universitas Kristen Petra Surabaya [3], telah melakukan penelitian dengan bahan bakar solar dan biodiesel minyak jarak menyatakan bahwa,Temperatur optimal pemanasan untuk solar adalah $50^{\circ} \mathrm{C}$, menghasilkan peningkatan daya dan torsi $2,54 \%$ dan penurunan konsumsi bahan bakar sebesar 2,35\%, efisiensi thermis sebesar 3,54\% dan penurunan konsumsi bahan bakar sebesar 3,11\%dan biodiesel $5 \%$ didapatkan temperatur optimal pemanasan $55^{\circ} \mathrm{C}$, menghasilkan peningkatan daya dan torsi sebesar 3,96\%, peningkatan efisiensi thermis sebesar $4,96 \%$ dan penurunan konsumsi bahan bakar sebesar 4,23\% serta pada biodiesel $10 \%$ dipanaskan dengan suhu optimal $60^{\circ} \mathrm{C}$, menghasilakan peningkatan daya dan torsi sebesar $1.98 \%$, peningkatan efisiensi thermal sebesar $7,44 \%$ dan penurunan konsumsi bahan bakar $6,46 \%$.

Serta hasil penelitian Yen Fie dari Universitas Kristen Petra Surabaya [4], telah melakukan penelitian di Laboratorium konversi energi dengan menggunakan mesin isuzu 2,5 direct injection dan menggunakan bahan bakar solar menyatakan bahwa, Dengan adanya pengendalian temperatur solar sebesar $54^{\circ} \mathrm{C}$ terjadi peningkatan daya dan torsi sebesar $1,91 \%$, efisiensi thermis sebesar $6,72 \%$ dan penurunan konsumsi bahan bakar sebesar 5,54\%. Dari beberapa hasil penelitian yang diuraikan diatas dapat disimpulkan bahwa dengan melakukan pemanasan bahan bakar dapat mempengaruhi performa motor diesel.

\section{METODOLOGI}

\subsection{Desain Penelitian}

Dalam penelitian ini yang digunakan adalah penelitian eksperimen dan studi perbedaan antara dengan pemanasan biosolar dengan dua suhu berbeda dibandingkan dengan suhu normal dengan ukuran suhu $55^{\circ} \mathrm{Cdan} 65^{\circ} \mathrm{C}$, dikenakan pada suatu objek penelitian yaitu pipa saluran bahan bakar sebelum pompa injeksi pada motor diesel 1 silinder (R175A DIESEL ENGINE).

\subsection{Variabel Penelitian}

\subsubsection{Variabel Bebas}

Variabel bebas adalah kondisi yang muncul akibat adanya suatu hubungan pada kejadian atau keaadaan yang diteliti, dalam penelitian ini yaitu daya, torsi dan konsumsi bahan bakar.

\subsubsection{Variabel Terikat}

Variabel terikat dalam penelitian ini adalah temperatur dari lilitan kawat nikelin yaitu:

a. Beban lampu

b. Temperatur Pemanas $55^{\circ} \mathrm{Cdan} 65^{\circ} \mathrm{C}$

\subsubsection{Variabel Kontrol}

Variabel kontrol adalah himpunan sejumlah gejala yang memiliki berbagai aspek atau unsur didalamnya yang berfungsi untuk mengendalikan agar variabel terikat yang muncul bukan karena 
variabel lain, tetapi karena variabel bebas. Variabel kontrol dari penelitian ini adalah pembebanan lampu mulai dari 600, 800, 1000 - 2800 watt.

\subsection{Alat Dan Bahan}

\subsubsection{Alat Penelitian}

1. $\quad$ Tool set kunci

Digunakan sebagai alat untuk melepas dan memasang komponen motor yang dipakai dalam pengujian.

2. Panel pembebanan lampu untuk membebani generator

3. Power analyzer untuk mengukur besarnya daya yang dikeluarkan oleh generator

\subsubsection{Bahan Penelitian}

1. Satu unit motor diesel dengan spesifikasi sebagi berikut :

$\begin{array}{lll}\text { a } & \text { Merk } & =\text { dongfeng } \\ \text { b } & \text { Perbandingan kompresi } & =23: 1 \\ \text { c } & \text { Diameter silinder } & =75 \mathrm{~mm} \\ \text { d } & \text { Panjang langkah piston } & =80 \mathrm{~mm} \\ \text { e } & \text { Sistem pembakaran } & =\text { injeksi langsung } \\ \text { f } & \text { Jumlah silinder } & =1 \text { silinder } \\ \text { g } & \text { Pendinginan } & =\text { air } \\ \text { h } & \text { Sistem star } & =\text { engkol }\end{array}$

2. Spesifikasi generator

$\begin{array}{lll}a & \text { Merk } & =\text { huafa } \\ \text { b } & \text { Power } & =3 \mathrm{KW} \\ \text { c } & \text { Voltage } & =230 \text { volt } \\ \text { d } & \text { Arus } & =13 \text { Ampere } \\ \text { e } & \text { Frekuensi } & =50 \mathrm{~Hz} \\ \text { f } & \text { Putaran } & =1500 \mathrm{r} / \mathrm{min}\end{array}$

3. Bahan bakar Biosolar.

4. Elemen pemanas

Elemen pemanas tersebut yang digunakan untuk memanaskan bio solar, komponen elemen pemanas tersebut terdiri dari plat stainles, relay, thermofuse, resistor, lampu, lilitan kawat nikelin, elemen pemanas dan pipa tembaga.

\subsubsection{Prosedur Penelitian}

Langkah kegiatan pengambilan data sebagai berikut:

1. Persiapkan alat dan bahan yang akan di gunakan.

2. Pasang alat pemanas dan hidupkan sampai suhu yang diinginkan.

3. Hidupkan motor diesel.

4. Mengatur pembebanan lampu pada panel.

5. Mengatur putaran (rpm) motor diesel dengan melihat power analizer sampai pada $\pm 50 \mathrm{~Hz} /$ (1500 rpm).

6. Pengambilan data pengujian

a waktu yang penggunaan bahan bakar solar sebanyak $10 \mathrm{cc}$.

b catat daya pada power analiser pada setiap pembebanan.

7. Kemudian atur kembali pembebanan lampu pada panel dan temperatur pemanas.

8. Setelah data terkumpul kemudian dipakai untuk menghitung daya, torsi dan konsumsi bahan bakar dengan rumus perhitungan unjuk kerja motor [5], sebagai berikut:

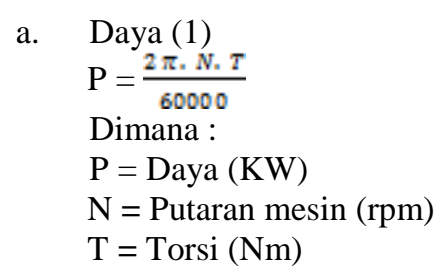


b. Torsi (2)

$\mathrm{T}=\mathrm{m} . \mathrm{g} \cdot 1(\mathrm{Nm})$

Dimana :

$\mathrm{M}=$ Massa $(\mathrm{kg})$

$\mathrm{g}=$ Percepatan grafitasi $\left(\mathrm{m} / \mathrm{s}^{2}\right)$

1 = Panjang lengan dynamometer $(\mathrm{m})$

karena pengujian menggunakan beban lampu maka torsi bisa dirumuskan (3)

$T(N . m)=\frac{\mathrm{p}(\mathrm{Kw}) \cdot 60000}{2 . \pi \mathrm{N}}$

c. Konsumsi bahan bakar spesifik dan laju konsumsi bahan bakar (4), (5)

$M f=\frac{b_{0} \cdot 3600}{t \cdot 1000} \cdot p b b$

$\mathrm{Sfc}=\frac{\mathrm{mf} f}{\mathrm{p}}$

Dimana :

$M f$ = laju konsumsi bahan bakar $(\mathrm{kg} / \mathrm{h})$

$P \mathrm{bb}=$ massa jenis bahan bakar

$S f c=$ bahan bakar yang dipakai

\section{HASIL DAN PEMBAHASAN}

\subsection{Analisa Perhitungan Daya Hasil Pengujian}

Dari hasil pengujian yang telah dilakukan, diperoleh daya yang dihasilkan motor dengan menggunakan kondisi mesin standart dan menggunakan pemanas bahan bakar sebelum pompa injeksi dengan variasi pemanasan $55^{\circ} \mathrm{C}$ dan $65^{\circ} \mathrm{C}$.untuk lebih jelasnya dapat dilihat pada Tabel 1 .

Tabel 1. Daya hasil pengujian

\begin{tabular}{cccc}
\hline \multirow{2}{*}{$\begin{array}{c}\text { Beban lampu } \\
\text { (Watt) }\end{array}$} & Standart & ${\text { Pemanasan } \mathbf{5 5}^{\circ} \boldsymbol{C}}^{\text {Daya }(\mathbf{W w})}$ & Pemanasan $_{\mathbf{6 5}}{ }^{\circ} \boldsymbol{C}$ \\
\cline { 2 - 4 } 600 & 0,796 & 0,804 & 0,811 \\
800 & 1,078 & 1,085 & 1,082 \\
1000 & 1,290 & 1,420 & 1,283 \\
1200 & 1,570 & 1,624 & 1,642 \\
1400 & 1,834 & 1,872 & 1,917 \\
1600 & 2,007 & 2,090 & 2,181 \\
1800 & 2,141 & 2,258 & 2,230 \\
2000 & 2,174 & 2,420 & 2,439 \\
2200 & 2,478 & 2,566 & 2,625 \\
2400 & 2,629 & 2,818 & 2,853 \\
2600 & 2,790 & 2,894 & 2,902 \\
2800 & 2,789 & 2,870 & 2,892 \\
Daya max(2600) & $\mathbf{2 , 7 9 0}$ & $\mathbf{2 , 8 9 4}$ & $\mathbf{2 , 9 0 2}$ \\
\hline
\end{tabular}

Pada tabel 1 ditunjukan bahwa daya maksimal meningkat pada beban 2600 watt. Dengan adanya penambahan alat pemanas terjadi peningkatan sebesar $3,5 \%$ dari kondisi standart pada suhu $55^{\circ} \mathrm{C}$, Sedangkan pada suhu $65^{\circ} \mathrm{C}$ terjadi peningkatan $3,8 \%$ dari kondisi standart. Secara teoritis dapat dijelaskan bahwa peningkatan ini disebabkan oleh pemanasan biosolar yang mengakibatkan viskositas biosolar menurun sehingga saat penginjeksian bahan bakar keruang bakar dapat membentuk butiranbutiran kabut bahan bakar yang lebih halus, dengan kondisi ini maka proses percampuran bahan bakar dan udara akan lebih homogen sehingga bahan bakar akan lebih mudah terbakar dan kerja dari poros engkol juga akan lebih ringan karena pemanasan mengakibatkan mudahnya bahan bakar di ijeksikan dan secara otomatis daya dari poros engkol dapat dimaksimalkan untuk menggerakan beban. 


\subsection{Analisa Perhitungan Torsi Hasil Pengujian}

Dari hasil pengujian dengan menggunakan motor kondisi standart dan menggunakan pemanas bahan bakar sebelum pompa injeksi dan menggunakan variasi pemanasan $55^{\circ} \mathrm{C}$ dan pemanasan $65^{\circ} \mathrm{C}$, telah diperoleh daya motor dan daya motor tersebut digunakan untuk menghitung torsi motor dengan (3), contoh sebagai berikut dan hasil perhitungan semua data tercantum dalam Tabel 2.

Tabel 2. Hasil perhitungan torsi

\begin{tabular}{cccc}
\hline \multirow{2}{*}{$\begin{array}{c}\text { Beban lampu } \\
\text { (Watt) }\end{array}$} & \multicolumn{3}{c}{ Torsi $(\boldsymbol{N . m})$} \\
\cline { 2 - 4 } & Standart & $\begin{array}{c}\text { Pemanasan } \\
\mathbf{5 5}^{\circ} \boldsymbol{C}\end{array}$ & $\begin{array}{c}\text { Pemanasan } \\
\mathbf{6 5}^{\circ} \boldsymbol{C}\end{array}$ \\
\hline 600 & 5,048 & 5,121 & 5,10 \\
800 & 6,866 & 6,910 & 6,89 \\
1000 & 8,216 & 9,044 & 8,17 \\
1200 & 10 & 10,34 & 10,45 \\
1400 & 11,681 & 11,92 & 12,21 \\
1600 & 12,783 & 13,31 & 13,89 \\
1800 & 13,636 & 14,38 & 14,20 \\
2000 & 13,847 & 15,41 & 15,53 \\
2200 & 15,783 & 16,34 & 16,71 \\
2400 & 16,745 & 17,94 & 18,17 \\
2600 & 17,770 & 18,43 & 18,48 \\
2800 & 17,764 & 18,28 & 18,42 \\
Torsi $\max (\mathbf{2 6 0 0})$ & $\mathbf{1 7 , 7 7 0}$ & $\mathbf{1 8 , 4 3}$ & $\mathbf{1 8 , 4 8}$ \\
\hline
\end{tabular}

Seperti terlihat pada pembahasan pada daya dan beban, bahwa torsi pun terpengaruh dengan adanya pemanasan bahan bakar. Karena torsi juga dipengaruhi oleh daya, semakin dayanya naik torsi pun juga ikut naik. Seperti dilihat torsi meningkat pada pemanasan $65^{\circ} \mathrm{C}$ yaitu sebesar $3,8 \%$ dari standart dan untuk pemanasan $55^{\circ} \mathrm{C}$ terjdi peningkatan $3,5 \%$ dari standart.

\subsection{Analisa Perhitungan Konsumsi Bahan Bakar Hasil Pengujian}

Dari hasil pengujian yang dilakukan, diperoleh waktu konsumsi bahan bakar yang digunakan untuk menghitung konsumsi bahan bakar atau Sfc. Proses pengambilan waktu konsumsi bahan bakar dengan menggunakan stopwatt dengan kapasitas sebesar $10 \mathrm{cc}$ yang terlihat pada buret. Pengujian ini menggunakan kondisi mesin standart dan menggunakan pemanas bahan bakar sebelum pompa injeksi dengan variasi pemanasan $55^{\circ} \mathrm{C}$ dan $65^{\circ} \mathrm{C}$. Perhitungan ini menggunakan daya motor $(\mathrm{P})$ untuk membagi $M f$ dengan (3) atau laju konsumsi bahan bakar dengan (5), maka hasil perhitungan dapat dilihat dibawah ini serta hasil semua perhitungan tercantum dalam tabel 3. Pada tabel 3 adanya kecenderungan $S f c$ sudah mulai turun pada saat pembebanan 800 watt hal ini disebabkan karena bahan bakar sudah dipanasi dahulu sebelum motor tersebut dihidupkan. Sehingga bahan bakar yang sudah dipanasi akan menjadi mudah terbakar sehingga membutuhkan waktu yang singkat untuk mencapai kondisi penyalaan sendiri.

Hal ini nantinya akan mengkompensasi keterbatasan waktu yang tersedia untuk pembakaran pada saat putaran tinggi sehingga prosentase bahan bakar dapat dikurangi dan daya yang dihasilkan juga lebih besar.

Dari tabel 3 ditunjukan bahwa dengan adanya pemanas bahan bakar terjadi penurunan konsumsi bahan bakar pada pemanasan $55^{\circ} \mathrm{C}$ terjadi penurunan konsumsi bahan bakar sebesar 3,5\% dari standart. Pada kondisi pemanasan $65^{\circ} \mathrm{C}$ juga terjadi penurunan konsumsi bahan bakar yang signifikan yaitu sebesar $29,4 \%$ dari kondisi standart. 
Tabel 3. Hasil perhitungan $S f c$

\begin{tabular}{cccc}
\hline \multirow{2}{*}{$\begin{array}{c}\text { Beban lampu } \\
\text { (Watt) }\end{array}$} & \multicolumn{3}{c}{$\boldsymbol{S f c}(\mathbf{K g} / \mathbf{K W h})$} \\
\cline { 2 - 4 } & Standart & $\begin{array}{c}\text { Pemanasan } \\
\mathbf{5 5}^{\circ} \boldsymbol{C}\end{array}$ & $\begin{array}{c}\text { Pemanasan } \\
\mathbf{6 5}^{\circ} \boldsymbol{C}\end{array}$ \\
\hline 600 & 0,656 & 0,628 & 0,533 \\
800 & 0,553 & 0,577 & 0,287 \\
1000 & 0,564 & 0,469 & 0,436 \\
1200 & 0,499 & 0,448 & 0,371 \\
1400 & 0,499 & 0,399 & 0,341 \\
1600 & 0,473 & 0,357 & 0,313 \\
1800 & 0,472 & 0,396 & 0,343 \\
2000 & 0,497 & 0,417 & 0,329 \\
2200 & 0,486 & 0,421 & 0,307 \\
2400 & 0,518 & 0,445 & 0,321 \\
2600 & 0,510 & 0,492 & 0,360 \\
2800 & 0,591 & 0,546 & 0,417 \\
Sfc max $\mathbf{( 2 6 0 0 )}$ & $\mathbf{0 , 5 1 0}$ & $\mathbf{0 , 4 9 2}$ & $\mathbf{0 , 3 6 0}$ \\
\hline
\end{tabular}

\section{KESIMPULAN}

Berdasarkan analisa dan perhitungan dari data-data yang telah diperoleh dari hasil penelitian yang telah dilakukan, pemanasan bahan bakar sebelum pompa injeksi maka dapat diambil kesimpulan sebagai berikut :

1) Pada hasil penelitian terhadap pemanasan bahan bakar sebelum pompa injeksi terdapat peningkatan daya sebesar $3,5 \%$ pada suhu $55^{\circ} \mathrm{C}$ dan $3,8 \%$ pada suhu $65^{\circ}$ dari kondisi standart.

2) Pada hasil penelitian terhadap pemanasan bahan bakar sebelum pompa injeksi terdapat peningkatan torsi sebesar 3,5\% dari standart pada suhu $55^{\circ} \mathrm{C}$ dan $3,8 \%$ dari standart pada suhu pada $65^{\circ} \mathrm{C}$.

3) Pada hasil penelitian terhadap pemanasan bahan bakar sebelum pompa injeksi terjadi penurunan konsumsi bahan bakar sebesar 3,5\% dari kondisi standart pada suhu $55^{\circ} \mathrm{C}$, sedangkan pada suhu $65^{\circ} \mathrm{C}$ terjadi penurunan konsumsi bahan bakar $29,4 \%$ dari kondisi standart.

\section{DAFTAR PUSTAKA}

[1] Febrian Wiilyanto, 1999, Peningkatan unjuk kerja motor diesel dengan penambahan pemanas solar, Universitas Kristen petra.

[2] Murni, 2010. Kajian eksperimental pengaruh temperatur bio diesel minyak sawit terhadap performasi mesin diesel direct injection putaran konstan, Universitas Diponegoro, Semarang.

[3] Stefanus Oki Suharjo, Pengaruh penambahan pemanas bahan bakar terhadap unjuk kerja motor diesel injeksi langsung, Universitas Kristen Petra, Surabaya.

[4] Yen Fie, Pengndalian temperatur bahan bakar untuk meningkatkan unjuk kerja mesin diesel injeksi langsung, Universitas Kristen Petra, Surabaya.

[5] Yuda setiawan, 2009, Pengaruh pemanasan bahan bakar, Sekolah Tinggi Teknik Wiworotomo, Purwokerto. 